Int. J. Electrochem. Sci., 15 (2020) 10707 - 10721

\title{
Cyclic Voltammetric and Spectroelectrochemical Studies of Tris(5-amino-1,10-phenantroline)Iron(II) Polymer Films
}

\author{
Kenneth L. Brown*, Rebecca Danforth, Evan Bleitz, Yechan Hwang and Dustin Rens \\ Hope College, Department of Chemistry, Holland, MI 494923 \\ "E-mail: brownk@hope.edu \\ doi: $10.20964 / 2020.11 .66$
}

Received: 30 June 2020 / Accepted: 8 September 2020 / Published: 30 September 2020

Tris(5-amino-1,10-phenantroline)iron(II) polymer films were prepared on glassy carbon electrodes and indium tin oxide (ITO) surfaces using cyclic voltammetry. The cyclic voltammograms collected during electropolymerization are correlated with the electrochemical and spectroelectrochemical characterization observations of the polymer films. On ITO surfaces, the films demonstrate reversible electrochromism switching between colors of red and yellow due to potential changes either in the cyclic voltammetry-scanning potential or pulsed-potential mode. Spectroelectrochemical measurements of the polymer films were made using tetraethyl- and tetrabutyl-ammonium perchlorate supporting electrolyte solutions. The absorbance at $506 \mathrm{~nm}$ is significantly diminished when measurements are made in tetrabutylammonium perchlorate supporting electrolyte solutions, indicating that spectroelectrochemical responses are limited by counterion diffusion within the polymer films.

Keywords: Electropolymerization, cyclic voltammetry, spectroelectrochemistry, indium tin oxide, polymer films

\section{FULL TEXT}

(C) 2020 The Authors. Published by ESG (www.electrochemsci.org). This article is an open access article distributed under the terms and conditions of the Creative Commons Attribution license (http://creativecommons.org/licenses/by/4.0/). 